\title{
COVID-19 and Most Affected Section of the Society
}

\author{
KaveriRusia $^{1}$, Dr. Swaroopa Chakole ${ }^{2}$ \\ ${ }^{1}$ Intern, Dept. of Community Medicine, Jawaharlal Nehru Medical College, DattaMeghe Institute of Medical \\ Sciences (Deemed to be University), Sawangi (Meghe), Wardha-442001, Maharashtra, India, \\ ${ }^{2}$ Professor, Dept. of Community Medicine, Jawaharlal Nehru Medical College, DattaMeghe Institute of Medical \\ Sciences (Deemed to be University), Sawangi (Meghe), Wardha-442001, Maharashtra, India, \\ Emails: ${ }^{1}$ kaverirusia12@gmail.com, ${ }^{2}$ drswaroopachakole@gmail.com, \\ Type of Article: Review \\ Conflict of Interest: None \\ Funding: DMIMS \\ Ethical Approval: IEC, DMIMS, Wardha.
}

\section{ABSTRACT \\ BACKGROUND}

COVID-19 or coronavirus disease 2019 is constantly emerging pandemic that has created unprecedented challenge in front of humanity as a whole. Extremely high spreading ability and high mortality rate and negative clinical outcomes is what mostly feared of.

\section{SUMMARY}

COVID-19 has affected almost every person directly or indirectly. The multispectral impact on human life is unprecedented. The differential impact on various strata of the society needed more vigorous study on it so that clear picture emerges out. The plight of migrant laborers and daily wagers were seen by many and consoled. The vulnerable section mentioned had negative effect on health, sociopolitical and economic aspect of their lives. More person are on the verge of extreme poverty than never before.

\section{CONCLUSION}

More philanthropic activity and poverty alleviating programs are needed to avoid widespread social distress among population. Sectional research and targeted delivery of schemes may be needed so that true beneficiary will get the benefit.

KEYWORDS:covid-19, pandemic, inequality, socioeconomic starta, poorer section, health, economic, mutation.

\section{INTRODUCTION}

The disease which shook the whole world by its lethal nature is named as coronavirus disease 2019 or COVID-19. The novel coronavirus has been wreaking the havoc since its inception in December 2019.(1) From unnamed pneumonia to pandemic, it deeply affected the lifestyle and changed the way of living of human being. The highly virulent nature and extremely lethal nature made the COVID-19 most fatal disease outbreak turned epidemic of the century. As of December 31, 2020, $82,849,128$ infection related to COVID-19 has been reported from across 200 countries and regions on the planet and $1,807,922$ mortalities have been reported so far from the COVID-19 related complications(2). United States of America India Brazil, Russian federation, FranceUnited Kingdom are the top six countries reporting more than half of the registered COVID-19 infection and case fatalities(3). Lax implementation of lockdown measures and defiance of various preventive measure guidelines along with huge population density are reasons attributed to the huge numbers being reported from these countries. On March 11, 2020, World Health 
Organization has upgraded the COVID-19 status from public health emergency of international concern (PHEIC) to pandemic after assessing the menace that it spread across the world(4). Pandemic has arrived with containment measures like lockdown and movement restrictions which are till date followed according to the ground situation. New coronavirus strainwhich is mutated has been reported from United Kingdom and South Africa(5). This has raise alarm as the new strain supposedly more virulent than the previous one. Previous strain had already killed more than a million people making it most lethal virus in near past. The impact of COVID-19 has been felt by all the people of the earth, directly or indirectly but the brunt that poorer and vulnerable section had faced is extremely huge. Lockdown(6) induced losses of jobs and livelihood has delivered devastating yet multi spectralimpact which will linger around for quite a while. The health and economic impact along with educational and psychological impact are most prominent one and can be seen among poorer cross section of the society. Rising inequality is over all a challenge and to prevent that to some extent and stay safeguarded from the long term implications of the COVID-19 infection preventive measure can prove to be effective. In this article we have taken a holistic overview of the current pandemic impact on poorer section and way forwards.

\section{MOST AFFECTED SECTION OF THE SOCIETY}

COVID-19 pandemic one of the gravest and fatal situations that has humanity faced since last century. Every aspect of the life has been affected of nearly all the people inhabiting the planet earth. The differential impact is necessary to be studied as some section of the society has been affected the most while some has been barely affected. Multispectral and cascading impact of this pandemic on most affected section of the society can be observed. This most affected section includes people from poorer economic background, low income category or people from war torn areas. The spectrum is even larger and includes low waged laborers, farm laborer, industry worker, hawkers, street vendors, rickshaw puller, beggars, homeless people, people residing in slum area, marginalized section, migrant workers, women in rural household, unorganized sector workers and laborers, daily wagers and so many more. These are the people with minimum security of everything. They earn during day time and eat with that earing only at night. They have low financial stability and literacy rate is quite low among these people. They don't know how to avail the benefits of various schemes that are launched by the governments to cover them under some sort of security net. Lack of awareness is huge among them. Covid19 pandemic has increased social, health and financial insecurities among them. Lack of resources and informal employment makes them most vulnerable. Already the chances of exploitation was seemingly high among these section of people, post pandemic situation only worsens the situation(7).

\section{VICIOUS CIRCLE OF HEALTH AND INCOME}

Health and income has intimate relationship and seeing separate with two different lenses would not serve justice to both of them. Chances of survival has a correlation to income level. The better is your income the more your chances of survival on earth increases. Also lifestyle and level of access to health care is also dependent on money one makes. People in bottom 40 to 50 percent of income pyramid have double chance of having poor health than their top 20 percent counterpart. Also poverty which is attached due to low income levels and comparatively high expenditure has an association with bad health outcomes. Poverty that is being persisted 
for long has more detrimental impact than the recent one. Health care and salary or income can affect each other. Lower income levels are reason behind poor health care, low social security protection and few chances of better health. Whereas poor health conditions can hamper with good employment and livelihood opportunities and in turn affects the income levels. All over the world, coronavirus has affected all the people either in direct way or indirect way. Prevalent condition of loss of livelihood and job of daily wagers, laborers, migrant workers, hawkers and pullers can be found. It is followed by deterioration of income and savings. Various governments had to freely open their food stocks through public distribution system as distressed people were finding it difficult to even earn for their daily food ration. Pandemic only aggravated the situation by infecting this strata of people(8). It is also seen that mortality rate of coronavirus disease 2019 or COVID-19 was considerably higher among population who are deprived of minimum necessary health care and present at the bottom of the socioeconomic ladder. Everyone has right to have good health and living conditions. But in contemporary situations many inequalities in the societies are culminating to denial of even basic necessities like basic health care, food and even shelter. Already the inequalities were sky rocketing and now after the brutal attack of COVID-19 it is now at unprecedented levels. The data shows us that before pandemic arrived employment rate has been increased but the type of employment has been reduced to contractual works. The gig economy where there is no obligation on employer to provide any kind of financial or health provident fund is gaining ground. More people are vulnerable than before due to such ad hoc system. Income levels are stagnated for working class. In a study conducted in United Kingdom observed that 65 percent of the families from lower most strata had savings less than one thousand and five hundred pounds(9). The novelty of the novel coronavirus has led to imposition of non-pharmacological interventions like lockdown and movement restrictions which shut down the industries and eventually every small business. Previous such economic closure of comparable level was found in 2008 subprime crisis. Study done in that period pointed out deterioration in health, morbidity, psychological distress which can be easily prevented by strong social security cushion. According to a study on cross section of the society, health is way better in top quarter and worse in bottom quarter, also outcome shows the same trend. Upper strata may survive rarest of rare disease and genetic disorder due to sheer power of incomebut lower starts how so ever fit can have to face extreme clinical outcome in petty disease due to lack of resources and access to good health care.Geographical distribution of health is also validate this trend(10). As rich countries likeOECD countries and western nations have advanced heath care infrastructure, their residence need not worry about flu's and other small diseases whereas least developed countriesand war torn countries of Africa and middle eastern countries or gulf nations have extremely poor health care infrastructure and their people live under extreme poverty. Also life expectancy at birth is also higher in developed countries than the developing as well as least developed counterpart. Income has indirect and direct effects on health. One experience fewer types of stress and anxiety as ones income level ha increases or remained at par with threshold. Various stresses may culminate into psychosocial problems in the matter of time, resulting into lowering of physical activity and dull mental state. Income is also linked with diet as higher income can buy good and nutritious diet which can not only protects you from diseases but also help in keeping the person mentally and 
physically active to give the perfect shot at every task further increasing the chances of raise in income. Whereas lower income can buy only staple food which cannot be healthy and leads to many chronic illnesses and stress may lead to addictions that are not good for health such as smoking and consuming cheap liquor which further worsens the situation and reduce physical as well as mental capacity which in turn may contribute to losing of livelihood due to poor performance at workplace.

Health is also considered as an asset which is attack by COVID-19 infection. It produces social as well as economic output. Poor health can restrict person fromgaining or keeping the job at hand. Also early childhood poor health may culminate into overall negative outcomes in a person's life. Poverty may persists in such situations(11).

\section{ECONOMIC IMPACT OF COVID-19 ON POORER SECTION}

COVID-19 has huge social as well as politico-economic impact on the human society. According to reports by World Bank around 50 million people may be pushed in extreme poverty by COVID-19 pandemic. The extremely quickly spreading ability or the virulence of the COVID-19 and it deadly nature has prompted various governments around the world to take some extreme and blanket measures like lockdown and movement restrictions has rendered almost major part of the worldlockup and shut down. This has multispectral impact on people especially poorer section of the society like daily wagers, migrant laborers, industry workers, hawkers andstreet vendors. The major chunk of the poor people that will be seen in near future due to pandemic will from existing poorer countries and some of the middle income countries(12). 23 millionif them will from sub-Saharan Africa where the economic health of the countries already marred by terrorism and secessionist tendencies and civil wars. Additional 16 million will from
SouthernAsiaparticularly from India, Pakistan, Bangladesh and Sri Lanka. Conflict ridden areas like Afghanistan, Syria, and Libya will harbor more than 10 million people which is huge as compared to their population. The measure of lockdown and movement restrictions had manifold effects including loss of jobs, remittance losses, rise in inflation, improper and irregular supply of foods, hindrance in providing health care services, educational losses etc. This effects were felt more strongly by urban and rural poor. For examples those depending on public distribution of the foods were made to starve as lockdown restrictions. Education was badly affected for those who dot have access to internet and mobile facility as e learning started to gain ground on the grounds of lockdown. Digital divide was widely seen as more privileged sections of the society were easily adapting to new situationsas they had financial cushion to absorb any shock that comesabruptly like COVID-19. Economic impact is faced by almost all households but poor households will have greater and long lasting impact which will ripple effect. There are urban and rural poor which are broad categories of vulnerable section. Though the penetration of the COVID-19 infection in rural areas is quite less, but is changing rapidly as more migration is being happening as infection may hit harder in rural areas too. Also they live in rural areas, means they have limited access to the health care facilities and if critical outbreak happens in rural areas where mainly people from lower socioeconomic strata resides, the health care system may find it hard to cope up with the situation. Most of the ruralhouseholds have some family members working in urban areas from where they send remittances to the rural home. Sometimes this remittance is the sole income of the family residing in the rural areas.As the lockdown induced job loss was observed, poverty is poised to increase its extent. In case of urban poor 
where access to health care is not a problem, their congested settlements and poor hygienic practices around them makes them more vulnerable as compares to their ruralcounterpart(13). Also COVID-19 had already overwhelmed all health care facility,accommodating that many people is a challenge that is already being faced by urban health care centers. Gig economy has already changed the nature of job with now having even low financial and social security coverage, the workers are literally defenestrated from the formal economy. Especially in middle income countries, which saw some poverty reduction due to percolation of wealth, are now on the verge of extreme poverty. This section of society highly depends upon services that are provided by the government, for example public distribution schemes for food, education, health and so on. Disruption in all these will have severe and detrimental impact. Children'scoming to school wereentitled to hot and cooked food which were the only nutritious food they get. Lockdown made schools to close, teachers and workers to work from home. So this important meal also vanished from the poorer sections entitlement.

\section{INEQUALITY AND COVID-19}

Sustainable development goals which are pending to achieved by year 2030 defines 17 SDG's which are extremely basic and should have been achieved so far but not yet. No poverty, zero hunger, gender equality, decent work and economic growth, reducing inequalities as a whole are some the widespread goals that covers basic yet important aspect of the human lives(14-16). Inequalities were rising faster, be it economic, income or health. Majority section of the society is currently living under substandard condition where on the other hand massive accumulation of health can be seen in few hands. Rallying cry of leaving no one behind has been given by United Nations but it needs a holistic participation and sustainable approach. Income inequalities among countries may have slightly positive trend as diffusion of wealth had happened but income inequalities in countries has risen at unprecedented scale. Various inequality has in fact increased post globalization for example age , origin, ethnic, disability, class, income, political indicating the few gainers over many losers. New technological inequalities like accessing digital technologies and internet can be prominently seen after pandemic has struck. Income equality has risen manifold within countries pointing again the gains of few over many(17-20). Densely populated areas of the world like Asia and Africa has seen massive inequality which only highlighted by COVID-19 pandemic.Global trend in income inequality has been consistently negative as top one percent of the populations holdsnearlyforty percent of the total wealth. The middle class trap can be seen reality as lower middle class is stuck where they are economically. Also they are most vulnerable to slip into the below poverty lone as the pandemic has caused widespread job losses(21-23). The signals that indicates income inequality are higher levels of poverty and disparate wealth distribution among population. COVID-19 has caused marginalized shops and petty stores to be closed and big firms were not that affected, but their workers were affected drastically as no financial cushion was provided to informal workforce.

\section{WAY FORWARD}

Pandemic has affecteddifferentially to all sections of the society. People on lower side of the lower socioeconomic strata has been drastically affected. Also the mutated new strain of the coronavirus has arisen the need of newer and more dynamic lockdown can be seen which in turn can derail more jobs and livelihood options. Also the long term implications should be taken into account while assessing thepandemics impact comprehensively. Several patients post discharge from the 
treatment of the COVID-19 had complained about various post illness complaints like fatigue, loss of intermittent taste and smell, reduced physical capacity, palpitations, occasional fever with cough and cold. Some clinical analysis also showed that weakening of cardiovascular muscles, myocarditis and various other severe other medical conditions $(24,25)$. Damage to alveolar tissue were also reported which in turn affects the oxygen supply to the various parts of the body. Therefore it is important to prevent the disease from happening at first place in order avoid these financially heavy burdens which poorer and marginalized section would not afford. If their physical activity is reduced due to infection their post COVID-19 job opportunities will get reduced. SO it is important to follow certain guidelines issued by competent agencies. Wearing of masks and personal and protective equipment's (PPE) kits can keep the coronavirus at bay. In fact its efficacy was seen in Ebola outbreak where it would have been impossible to trace the Ebola patients. It's Efficacy and effectiveness was also observed inCOVID19 pandemic as many were prevented from the coronaviruses infection. The lethal nature of the infection may provoke all sections of the society to protect themselves as there is no incentives in getting contracted by the infection(17). Few of the related studies on treatment aspects were reported $(26,27)$.

\section{CONCLUSION}

It is now established by various observations that poorer section has been more drastically affected than any other section of the society. Several million people are on the verge of slipping into poverty that is a grave cause of concern. Many are not able fulfill their basic needs of food, clothing and shelter, whichshould be the prime responsibility in the times of pandemic of not only government but also non-governmental agencies and civil society members because government has limited resources. Free food scheme is being run by several countries affected due to COVID-19 induced lockdown and should not be discontinued. Instead universal food coverage must ensure to guarantee that no person shall sleep empty stomach. Second revival of economic activities must be aided with proper policies and guidelines. As a long term goal,reducingvarious inequalities must be prioritize in order to inculcate this as a policy measure. Sustainable development goals should be achieved before due date and foe that stakeholder consolations can be done in order to ensure best outcome. Finally sustainable development is the only development that will help the humanity o sustain as over encroachment and exploitation had brought us here in pandemic situations. Lessons must be earnt from thisand rectification in policy measures as well as lifestyle changes can bring us at better position.

\section{REFERENCES}

1. Dushyant Bawiskar, Pratik Phansopkar, Ayurva Vilas Gotmare. COVID-19 Facets: Pandemics, Curse and Humanity. Int J Res Pharm Sci. 2020 Aug 6;11(SPL1):385-90.

2. COVID-19 Map [Internet]. Johns Hopkins Coronavirus Resource Center. [cited 2020 Dec 31]. Available from: https://coronavirus.jhu.edu/map.html

3 . WHO Coronavirus Disease (COVID19) Dashboard [Internet]. [cited 2020 Dec 31]. Available from: https://covid19.who.int

4. WHO Director-General's opening remarks at the media briefing on COVID-19 - 11 March 2020.pdf.

5. Wise J. Covid-19: New coronavirus variant is identified in UK. BMJ [Internet]. 2020 Dec 16 [cited 2020 Dec 23];371:m4857. Available from: https://www.bmj.com/content/371/b mj.m4857 
6. The Lancet null. India under COVID-19 lockdown. Lancet Lond Engl. 2020 25;395(10233):1315.

7. Ahmad K, Erqou S, Shah N, Nazir U, Morrison AR, Choudhary G, et al. Association of poor housing conditions with COVID-19 incidence and mortality across US counties. PLOS ONE [Internet]. 2020 Nov 2 [cited $2020 \quad$ Dec 30];15(11):e0241327. Available from:

https://journals.plos.org/plosone/articl e? id=10.1371/journal.pone.0241327

8. Coronavirus vs. inequality [Internet]. UNDP. [cited 2020 Dec 30]. Available from: https://feature.undp.org/coronavirusvs-inequality/

9. COVID-19 will hit the poor hardest. Here's what we can do about it [Internet]. [cited 2020 Dec 30]. Available from: https://blogs.worldbank.org/voices/co vid-19-will-hit-poor-hardest-hereswhat-we-can-do-about-it

10. India IF. How has Covid-19 crisis affected the urban poor? Findings from a phone survey [Internet]. Ideas For India. [cited 2020 Dec 30]. Available from: http://www.ideasforindia.in/topics/po verty-inequality/how-has-covid-19crisis-affected-the-urban-poorfindings-from-a-phone-survey.html

11. Finch WH, Hernández Finch ME. Poverty and Covid-19: Rates of Incidence and Deaths in the United States During the First 10 Weeks of the Pandemic. Front Sociol [Internet]. 2020 [cited 2020 Dec 30];5. Available from: https://www.frontiersin.org/articles/1 0.3389/fsoc. $2020.00047 /$ full

12. Bambra C, Riordan R, Ford J, Matthews F. The COVID-19 pandemic and health inequalities.J Epidemiol Community Health [Internet]. 2020 Nov [cited 2020 Dec 30];74(11):964-8. Available from: https://www.ncbi.nlm.nih.gov/pmc/ar ticles/PMC7298201/

13. Buheji M, Cunha K, Mavrić B. The Extent of COVID-19 Pandemic Socio-Economic Impact on Global Poverty.A Global Integrative Multidisciplinary Review.Am J Econ. 2020 Apr 30;10:213-24.

14. THE 17 GOALS | Sustainable Development [Internet]. [cited 2020 Dec 31]. Available from: https://sdgs.un.org/goals

15. Inequality - Income inequality OECD Data [Internet]. theOECD. [cited 2020 Dec 31]. Available from: http://data.oecd.org/inequality/incom e-inequality.htm

16. Palmer $\mathrm{K}$, Monaco A, Kivipelto $\mathrm{M}$, Onder G, Maggi S, Michel J-P, et al. The potential long-term impact of the COVID-19 outbreak on patients with non-communicable diseases in Europe: consequences for healthy ageing. Aging Clin Exp Res. 2020 Jul;32(7):1189-94.

17. Güner R, Hasanoğlu I, Aktaş F. COVID-19: Prevention and control measures in community. Turk $\mathbf{J}$ Med Sci. 2020 Apr 21;50(SI-1):571-7.

18. Bakshi, S., V. Toshniwal, A. Agrawal, S. Acharya, and S. Shukla. "Awareness and Psychosocial Effects of Covid-19 Pandemic on Health Care Professionals and Medical Students across the State of Maharashtra." International Journal of Current Research and Review 12, no. 22 Special Issue (2020): S-122-S125.

https://doi.org/10.31782/IJCRR.2020. SP74.

19. Balsara, K., and D. Shukla. "Stepping up Detection, Response, Preparedness and Readiness Measures for 'Covid19'-a Pandemic.” International Journal of Research in Pharmaceutical Sciences 11, no. Special Issue 1 (2020): 1042-47. https://doi.org/10.26452/ijrps.v11iSPL 1.3442 . 
20. Bawari, H., and J.N. Chaple. "Covid19 and the Aching World." International Journal of Research in Pharmaceutical Sciences 11, no. Special Issue 1 (2020): 253-58. https://doi.org/10.26452/ijrps.v11iSPL 1.2709 .

21. Bawiskar, D., P. Phansopkar, and A.V. Gotmare. "Covid-19 Facets: Pandemics, Curse and Humanity." International Journal of Research in Pharmaceutical Sciences 11, no. Special Issue 1 (2020): 385-90. https://doi.org/10.26452/ijrps.v11iSPL 1.2731 .

22. Bawiskar, N., A. Andhale, S. Acharya, S. Kumar, and S. Shukla. "Haematological Manifestations of COVID 19 and Their Prognostic Significance-a Cross-Sectional Study." International Journal of Research in Pharmaceutical Sciences 11, no. Special Issue 1 (2020): 918-22. https://doi.org/10.26452/ijrps.v11iSPL 1.3131 .

23. Bhatero, D., P. Sawarkar, and G. Sawarkar. "Indian Lifestyle with Ayurveda Perspective during COVID19 Pandemic." International Journal of Research in Pharmaceutical Sciences 11, no. Special Issue 1 (2020): 139699.

https://doi.org/10.26452/ijrps.v11iSPL 1.3668 .

24. Bhokardankar, P., B. Rathi, M. Khan, and R. Rathi. "COVID-19 Pandemic: Home Remedies for Immunity Boosting." International Journal of Research in Pharmaceutical Sciences 11, no. Special Issue 1 (2020): 734-38. https://doi.org/10.26452/ijrps.v11iSPL 1.3075 .

25. Bhutada, R.S., R. Rathi, and D. Dasar. "Immunity Boosting Diet during COVID 19." International Journal of Research in Pharmaceutical Sciences 11, no. Special Issue 1 (2020): 832-38. https://doi.org/10.26452/ijrps.v11iSPL 1.3089 .
26. Biswas, A., and K. Chandankhede. "Dietary and Living Regimen of COVID-19 with Special Reference to Ayurveda Varsha and Sharad Ritucharya." International Journal of Research in Pharmaceutical Sciences 11, no. Special Issue 1 (2020): 758-62. https://doi.org/10.26452/ijrps.v11iSPL 1.3079 .

27. Boharupi, G., and P. Shelotkar. "Immunomodulatory Measures to Strengthen the Body during Covid Outbreak." International Journal of Research in Pharmaceutical Sciences 11, no. Special Issue 1 (2020): 774-78. https://doi.org/10.26452/ijrps.v11iSPL 1.3081 